\title{
RELATORIO DA BIBLIOTHECA
}

\section{Exmo. Sr. Director}

Cumprindo a ordem de V Excia., tenho a honra de apresentar o relatorio do movimento da Bibliotheca da Faculdade de Direito, durante o anno findo de 1936, e, tambem, de tudo quanto se registou nas diversas secções subordinadas a esta chefia technica.

\section{SITUAÇÃO DA BIBLIOTHECA}

Accentuaram-se os serviços, em 1936, com grande augmento em relação aos do anno anterior. A secção technica teve de procurar fórma de mais efficiencia no controle geral, afim de não haver dispersão de trabalho nem de tempo. Tudo está sob a immediata orientação desta chefia, desde a redacção da correspondencia até a distribuição da "Revista" e do "Annuario", da Faculdade de Direito.

No tocante ás relações com as instituições congeneres, a Bibliotheca desenvolveu largamente o intercambio de publicações, para o que tem sido factor de valia a "Revista da Faculdade de Direito"

Quanto á actualização, é de notar que foram adquiridas as principaes obras de direito editadas em 1936, bem como se acham em dia quasi todas as revistas e publicações periodicas. A actualização da Bibliotheca é das razões do crescimento diario do numero de frequentadores e consulentes.

Presentemente, existem 21.852 obras, em 44.732 volumes, avaliados em cerca de 3 mil contos de reis.

\section{FREQUENCIA E CONSULTAS}

A frequencia, em 1936, foi de 50.550 pessoas, das quaes 39.660 no periodo diurno e 10.930 no periodo nocturno. Como 
em 1935 a frequencia foi de 28.347 pessoas, verifica-se, agora, o augmento de 22.203 consultantes.

Dos frequentadores, 28.671 estudantes, 8.305 estranhos e 13.574 leitores de jornaes.

Foram requisitadas, pelos consulentes, 40.813 obras, em 47.616 volumes, das quaes apenas 2.475 de literatura. As de sciencias juridicas e sociaes attingiram 29.412.

Deram-se 69 consultas bibliographicas escriptas.

Tudo conforme o mappa annual e os mappas mensaes remettidos já a V. Excia.

Incentivou-se a propaganda da Bibliotheca, e, para isso, foi apreciavel o concurso dos jornaes e das radiodiffusoras da Capital.

\section{CATALOGO ONOMASTICO}

Em maio, terminou o serviço de refazimento integral do catalogo onomastico. Segundo o plano desta chefia technica, o novo catalogo abrange, tambem, parte de fichas didascalicas (de titulos das obras de anonymos e das publicações periodicas) e outra de fichas ideographicas (de certos assumptos, como codificação, legislação, regulamentação, etc.), de sorte que, assim combinado, torna muito facil a pesquisa.

Foram accrescentadas mais de $\mathbf{3 0}$ mil fichas tabelladas e 5 mil cerca de arrazoados com resumo da materia principal.

Tinha o catalogo, ao ser concluido, mais de $100 \mathrm{mil}$ fichas, de cartolina de cor de rosa, dactylographadas. Entretanto, com a fichagem das obras e dos artigos no decorrer do anno, o numero de fichas excede já $200 \mathrm{mil}$.

\section{CATALOGO METHODICO}

Este catalogo (de fichas brancas) foi inteiramente reformado e teve o accrescimo de novas secções, sobretudo na parte do direito eleitoral. 0 exame das fichas antigas evi- 
denciou os muitos erros de classificação, e esse era dos motivos que difficultavam a consulta.

Com o desdobramento de assumptos a que obriga o systema decimal de Dewey, contém o catalogo mais de $250 \mathrm{mil}$ fichas.

No decorrer de 1937, serão refeitas as fichas antigas, hoje revista sob rigorosa reclassificação.

\section{FICHARIOS}

Por imprestaveis os velhos, adquiriram-se novos ficharios: 9 para o catalogo methodico e 8 para o catalogo onomastico.

São conjuntos de 6 gavetas, inteiramente de aço, modelo especial, assentes as gavetas em corrediças com rodizios de espheras de aço e providos de porta etiquetas.

\section{OBRAS ENTRADAS}

Em 1936, entraram 1.461 obras e 732 revistas: 417 por compra, 629 por doação e 415 por permuta com duplicatas da Bibliotheca e com a "Revista da Faculdade de Direito"

\section{SECÇÃO BIBLIOLATRICA}

Proseguiu, com resultados bons, o serviço de restauração, desinfecção e conservação dos livros. Para a desinfecção tem sido empregada a estufa thermo-chimica e, tambem, a pincelagem de fórmula especial com o uso de querozene e gazolina.

Sendo a desinfecção feita por serventes que não podem dedicar-se exclusivamente a esse serviço, parce-me conveniente entregal-o a pessoal com esse unico encargo. 


\section{ENCADERNAÇõES E RECONSTITUIÇõES}

Fizeram-se, na officina annexa á Bibliotheca, 841 encadernações e 458 reconstituições. Fóra, nas officinas de João Ignacio das Dores e Cid Pereira Lopes e na Penitenciaria do Estado, 1.169 encadernações.

Existem numerosos livros raros que carecem de restauração e reconstituição, antes que os estragos se tornem irreparaveis. Trata-se, notadamente, de volumes que vieram da primitiva bibliotheca do Convento de São Francisco, entre os quaes preciosas edições da Biblia e de theologia.

A crescente entrada de obras e revistas demonstra a necessidade do augmento de recursos da officina de encadernação. A compra de varias machinas melhor a apparelhou em 1936. E' indispensavel, agora, a acquisição de material para douração, afim de ser mais bem acabado o trabalho de encadernações.

Foi construida, na officina, uma galeria de madeira para aproveitamento do espaço.

\section{HEMEROTHECA}

Proseguiu, com optimos resultados, o serviço de recorte de jornaes e revistas que não teem collecções. Collados em esqueletos, classificados e fichados, constituem os artigos fonte de estudos muito consultada.

o numero de jornaes recebidos, diariamente, sobe a 117. Desses, vão para as collecções os exemplares de "O Estado de São Paulo", "Correio Paulistano" e "Jornal do Commercio", do Rio de Janeiro. Os demais são aproveitados na hemerotheca.

Das velhas collecções encostadas, parte foi encadernada e parte se encontra em encadernação. São collecções do "Commercio de São Paulo", "Correio Mercantil", "Diario Mercantil”, "Jornal do Commercio" (São Paulo), "O São Paulo" e "A Tribuna" (1902-1904), de Santos. 


\section{SECÇÃO TECHNICA}

Todo o movimento da Bibliotheca está sob o controle directo da chefia technica. $O$ desenvolvimento assim $o$ impõe, visto como o director interno tem de attender a tudo, afim de que os serviços não tenham solução de continuidade.

Além da classificação das obras, artigos e revisão das fichas, o chefe technico tem a seu cargo a redacção da correspondencia official, a fiscalização dos serviços de encadernação e reconstituição de obras, de hemerotheca e biblioiatria, as consultas bibliographicas por escripto, a orientação do intercambio de publicações e da remessa da "Revista" e do "Annuario"

\section{EXPEDIENTE}

A secção do expediente tem a seu cargo o registo das obras entradas e a expedição da correspondencia, da "Revista" e outras publicações.

\section{CORRESPONDENCIA}

Foi o seguinte o movimento da correspondencia da Bibliotheca, em 1936: cartas e officios recebidos, 574; expedidos, 3.827; total, 4.442 .

\section{CAIXA DE SELLOS}

As despesas de sellos e outros sommaram a importancia de rs. 3:000\$400.

\section{REQUISIÇõES DE MATERIAL}

Foram feitas diversas requisições de material ao Almoxarifado, conforme o annexo respectivo. 


\section{MOVEIS E UTENSILIOS}

Foram feitas requisições correspondentes ás necessidades do apparelhamento interno.

\section{"REVISTA DA FACULDADE DE DIREITO"}

A distribuição da "Revista" alargou-se, consideravelmente, com o envio a instituições nacionaes e estrangeiras e, bem assim, a personalidades notaveis. Está sendo remettida a todos os 'ministros da Côrte Suprema e do Superior Tribunal Eleitoral, aos desembargadores das Côrtes de Appellação estadoaes, a lentes de escolas de direito, aos juizes do Districto Federal e das capitaes dos Estados, a todos os juizes e Subsecções da Ordem dos Advogados do Estado de São Paulo.

Foram enviadas, ainda, com a devida autorização de V Excia., collecções completas a diversas instituições que as pediram. Do effeito dessa iniciativa, dizem bem as referencias recebidas por cartas e officios.

Foram remettidos exemplares, em consignação, a livrarias desta capital. A arrecadação da venda está a cargo da thesouraria da Faculdade.

Distribuem-se, de cada numero da "Revista", 1.415 exemplares: 418 para o estrangeiro, 39 a editores do Brasil e de outros paizes, e os restantes para o Brasil.

Em 1936, a distribuição accusou o total de 3.396 exemplares.

\section{“ANNUARIO DA FACULDADE DE DIREITO"}

Foi feita, regularmente, a divulgação do "Annuario" Distribuiram-se, em 1936, 271 exemplares. 


\section{INTERCAMBIO DE PUBLICAÇõES}

E' serviço de vantagem para a Bibliotheca. A toda remessa de publicações corresponde o recebimento de outras. Pedidos endereçados a autores de theses e outras publicações de direito obtiveram o envio de exemplares que a $\mathrm{Bi}$ bliotheca tem remettido através do intercambio.

Distribuiram-se 1.400 exemplares de theses e outras publicações, em 1936.

\section{PESSOAL}

Em 31 de dezembro de 1936, era o que segue o quadro do pessoal da Bibliotheca:

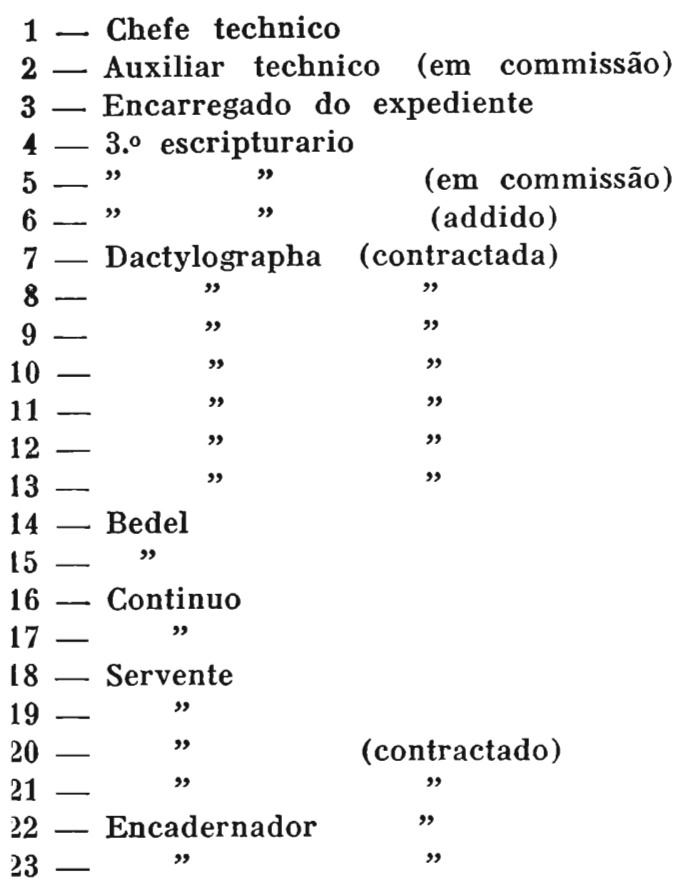

Verificaram-se, em 1936, as seguintes alterações no quadro do pessoal: em 17 de janeiro, exoneração, a pedido, do
António Constantino João Pedro Veiga Pacheco Herculano S. Mello Migue] Rogerio F. Guimarães Adolpho Schmidt Junior Noemia Corrêa Conceição Lilly Dale Terrell Mariá José do Amaral Santos Rosa Sophia Gennari Juracy Cardoso Almeida Barros Conceição Negrão Octavia de Azevedo Elias Apollinario Rodrigues Pedro Arruda Mello Jesuino Rodrigues Luiz Bottini Maximiliano Meneses Cassio Ignacio da Silva Jayme Pontes Amelio Ignacio Dilles René Pereira Lopes Adelphino Teixeira da Silva Agilulpho Candido Dias 
continuo Aulete Penteado; na mesma data, assumiu o mesmo cargo, por promoção, o continuo Luiz Bottini; em 18 de fevereiro, desligada da Bibliotheca para a Secretaria, a dactylographa contractada Ady Pinheiro Cortez; na mesma data, comtractada em substituição, a dactylographa Conceição Negrão; em 13 de agasto, nomeado o servente Cassio Ignacio da Silva, anteriormente contractado; em 3 de junho, commissionado, no cargo de auxiliar technico, o 3. escripturario João Pedro da Veiga Pacheco; e, em 25 de julho, commissionado, no cargo de $3 .^{\circ}$ escripturario, o $4 .^{\circ}$ escripturario Miguel Rogerio de Freitas Guimarães.

São Paulo, 31 de março de 1937. 